\title{
MODELAMIENTO COMPUTACIONAL DE LA CRUZIOSEPTINA CC-17 EXTRAÍDA DE LA RANA Cruziohyla calcarifer
}

\section{COMPUTATIONAL MODELING OF CRUZIOSEPTIN CC-17 EXTRACTED FROM THE FROG Cruziohyla calcarifer}

\author{
Camila Reinoso D. ${ }^{1}$, Sebastián Cuesta H. ${ }^{1}$, \\ Carolina Proaño-Bolaños ${ }^{2,3} \&$ Lorena Meneses O. ${ }^{*}$
}

Recibido: 29 de abril 2021 / Aceptado: 1 de julio 2021 10.26807/ia.v9i2.214

Palabras clave: acoplamiento molecular, anuro, exudado, péptidos antimicrobianos, propiedades fisicoquímicas Keywords: anuran, antimicrobial peptides, molecular docking, physicochemical properties, skin secretion

\section{RESUMEN}

El inadecuado uso de antibióticos ha conducido a un aumento en la tasa de resistencia bacteriana por esto ha sido fundamental el estudio de nuevos compuestos con propiedades bioactivas que permitan enfrentar el desafío ocasio-

1 Pontificia Universidad Católica del Ecuador, Facultad de Ciencias Exactas y Naturales, Escuela de Ciencias Químicas, Laboratorio de Química Computacional, Quito, Ecuador (dcrd-98@hotmail.es; sebastian_cuesta@yahoo.com; *correspondencia: Immeneses@puce.edu.ec)

2 Universidad Regional Amazónica IKIAM, Tena, Ecuador (carolina.proano@ikiam.edu.ec)

3 Queen's University Belfast, School of Pharmacy, Natural Drug Discovery Group, Belfast, UK (carolina.proano@ikiam.edu.ec) 
nado por la falta de fármacos efectivos para el tratamiento de infecciones causadas por un amplio rango de bacterias. En este sentido, el presente trabajo de investigación se centra en el modelamiento computacional de la Cruzioseptina CC-17 perteneciente a la familia de péptidos identificados en el exudado de la rana Cruziohyla calcarifer. Inicialmente, se realizó la caracterización del péptido en función de sus propiedades fisicoquímicas y la elucidación de su estructura secundaria, asimismo, para analizar la actividad del péptido se desarrolló el estudio de acoplamiento molecular de la Cruzioseptina CC-17 con enzimas presentes en Escherichia coli, Staphylococcus aureus, Candida albicans y con moléculas pertenecientes a la membrana celular bacteriana. Los resultados muestran que la Cruzioseptina CC-17 es un péptido cuya estructura secundaria está compuesta predominantemente por regiones alfa helicoidales y presenta una carga de +2 lo cual le concede el carácter básico, presenta un punto isoeléctrico de 8,6 y está compuesta en un 52,7 \% por aminoácidos hidrofóbicos. Finalmente, el estudio de acoplamiento molecular demuestra que la bioactividad del péptido puede explicarse en base a un mecanismo de ataque focalizado en la membrana celular bacteriana en donde la lisis celular se logra gracias a las interacciones electrostáticas entre la Cruzioseptina CC-17 con los distintos componentes de la membrana bacteriana.

\section{ABSTRACT}

The inappropriate use of antibiotics has led to an increase in the rate of bacterial resistance, therefore, the study of new compounds with bioactive properties has been essential to face the challenge caused by the lack of effective drugs for the treatment of infections caused by a wide range of bacteria. In this sense, the present research work focuses on the computational modeling of Cruzioseptin CC-17 belonging to the family of peptides extracted from the exudate of the Cruziohyla calcarifer frog. Initially, the characterization of the peptide was carried out based on its physicochemical properties and the elucidation of its secondary structure. In addition, molecular docking was performed to analyze the activity of the different enzymes present in Escherichia coli, Staphylococcus aureus and Candida albicans and with molecules present in the bacterial cell 
membrane. The results show that Cruzioseptin CC-17 is a peptide which secondary structure is predominantly composed of alpha helical regions and has a net charge of +2 which gives it the basic character, has an isoelectric point of 8.6 and is composed of a $52.7 \%$ by hydrophobic amino acids, which confirms its cationic character. In the other hand, molecular docking results shows that the bioactivity of the peptide can be explained based on a concentrated attack mechanism on the bacterial cell membrane where the cell lysis occurs by the electrostatic interactions between Cruzioseptin CC-17 with the different molecules of the cell membrane.

\section{INTRODUCCIÓN}

La resistencia antimicrobiana se ha convertido en uno de los problemas de mayor importancia en el campo de la salud pública. Los datos proporcionados por Centros para el Control y la Prevención de Enfermedades (CDC por sus siglas en inglés) son un reflejo claro de esta problemática pues se considera que cada año en los Estados Unidos al menos 2,8 miIlones de personas contraen una infección resistente a los antibióticos mientras que más de 35000 personas mueren (CDC, 2020). Este es un resultado de la constante evolución biológica sumada al uso inadecuado de antibióticos que ha desencadenado una serie de cambios a nivel genético en los diversos microorganismos y por ende el aumento de las tasas de resistencia antimicrobiana (Lewies, Du Plessis \& Wentzel, 2019).

Dado que la efectividad de los antibióticos convencionales se ha visto severamente mermada (Lei et al., 2019), la comunidad científica ha centrado su interés en el estudio de compuestos bioactivos tales como los péptidos antimicrobianos (AMP), que representan a las moléculas orgánicas que forman parte del sistema de la respuesta inmune innata de una amplia gama de organismos como anfibios, insectos, hongos, moluscos, artrópodos, vertebrados y plantas (Wang, 2020). Los AMP se encuentran formados por cadenas de entre 8 
a 45 aminoácidos los cuales no únicamente se destacan por presentar un amplio espectro de actividad antimicrobiana y por proporcionar protección contra bacterias, hongos, parásitos y virus (Datta \& Roy, 2020), sino que también tienen un rol importante en la inhibición de células cancerígenas (Zhang, Yang \& Ericsson, 2019).

Además, los péptidos antimicrobianos se caracterizan por presentar una carga neta que oscila entre +1 y +9 junto con propiedades catiónicas, hidrofóbicas y anfipáticas cuyo estudio es sumamente importante, ya que son los factores determinantes en su actividad frente a los distintos microorganismos patógenos (Koehbach \& Craik, 2019). Se debe resaltar que estos compuestos pueden presentar estructuras primarias, secundarias y terciarias muy diversas pero pueden clasificarse en cuatro clases principales: los péptidos que presentan una estructura secundaria lineal $\alpha$-helicoidal; aquellos que presentan estructuras lineales extendidas, es decir que se encuentran desprovistas de elementos $\alpha$ o $\beta$ pero que son ricas en aminoácidos como la glicina, arginina, triptófano o prolina (Koehbach
\& Craik, 2019); los péptidos cuya estructura pertenece a una lámina $\beta$ que es estable gracias a la presencia de uno o varios enlaces disulfuro; $y$ finalmente se encuentran los péptidos que presentan una estructura mixta conformada por una región $\alpha$ y una región $\beta$ (Lee, Hall \& Aguilar, 2015).

Los modelos propuestos para el mecanismo de acción de los AMPs se extienden desde la formación clásica de poros (Raheem \& Straus, 2019), hasta aquellos que involucran la acción de fuerzas electrostáticas (De Paula \& Valente, 2018), sin embargo, estos se pueden clasificar en dos grandes grupos en donde se encuentran mecanismos centrados en el ataque directo a la membrana y aquellos que involucran funciones de inmunomodulación (Kumar, Kizhakkedathu \& Straus, 2018).

Muchos péptidos con propiedades antimicrobianas han sido aislados a partir de anfibios pues estos se caracterizan por poseer gándulas granulares (Varga, Bui-Marinos \& Katzenback, 2019), las cuales, además de ser las encargadas de mantener el equilibrio iónico, son las responsables de proteger a estas especies con- 
tra la abrasión y agentes patógenos, al ser propulsoras de la producción de compuestos biológicamente activos que pueden llegar a presentar propiedades fungicidas y bactericidas (Demori et al., 2019).

En este sentido, las Cruzioseptinas (CZS) son una nueva familia de péptidos, extraídas a partir del exudado de la rana, Cruziohyla calcarifer pertenecientes a la familia Phyllomedusinae. Actualmente, se han reportado alrededor de 14 Cruzioseptinas, que se caracterizan por estar compuestas por una cadena peptídica de entre 20 a 32 aminoácidos y por poseer una secuencia $\mathrm{N}$-terminal única compartida. Asimismo, los distintos estudios microbiológicos realizados demues- tran que presentan un amplio espectro de actividad antimicrobiana frente a patógenos como el Staphylococcus aureus y la levadura Candida albicans y en menor medida frente a Escherichia coli (Proaño-Bolaños et al., 2016).

En el presente estudio, se emplean distintos métodos computacionales para caracterizar a la Cruzioseptina CC-17 con respecto a sus propiedades fisicoquímicas y estructura secundaria, así como también se analiza el mecanismo de acción con base en los resultados obtenidos mediante técnicas de acoplamiento molecular con enzimas inhibitorias de patógenos y moléculas presentes en la membrana celular bacteriana.

\section{MATERIALES Y MÉTODOS}

Para llevar a cabo el estudio computacional de la Cruzioseptina CC-17 se emplearon distintos recursos computacionales como servidores web (Pep Calc y Biosyn), bases de datos (Protein Data Bank), herramientas de visualización molecular (Pymol y Autodock Tools), softwares especializados en cálculos mecano cuánticos (Gaussian 09) y herramientas enfoca- das en el acoplamiento molecular (Autodock Vina), con los cuales se logró caracterizar el péptido en función de sus propiedades fisicoquímicas y en base a su interacción con una serie de moléculas presentes en la membrana celular bacteriana.

Los servidores web Pep Calc (Lear \& Cobb, 2016) y Biosyn (Bio-Synthesis, 
2010) fueron usados para la predicción de propiedades fisicoquímicas tales como la carga neta, el punto isoeléctrico, flexibilidad, probabilidad de superficie y composición de la secuencia de aminoácidos.

La predicción de la estructura secundaria se realizó empleando los servidores web Predict Protein (Yachdav \& Rost, 2013) y JPred 4 (Drozdetskiy, Cole \& Procter, 2015) con lo cual se determinó las regiones alfa helicoidales y giros beta presentes en el péptido.

El modelamiento computacional de la estructura de la Cruzioseptina CC17 se realizó por medio del software Pymol (Schrödinger, 2017) mientras que la optimización de cada una de las estructuras tridimensionales correspondientes al péptido y a las moléculas presentes en la membrana celular bacteriana fue realizada mediante el software Gaussian09 (Frisch et al., 2016) haciendo uso del método híbrido ONIOM en dos niveles HF/3-21G//HF/6-31G.

Por último, se efectuó el estudio de acoplamiento molecular, para lo cual se seleccionaron dos enzimas presentes por cada patógeno de interés y cuyas estructuras tridimensionales fueron obtenidas a partir de la base de datos RCSB Protein Data Bank (Berman et al., 2002). Con la ayuda del software Autodock Tools (Morris et al., 2009) se crearon los archivos de entrada para posteriormente ejecutar los cálculos en AutoDock VINA (Trott \& Olson, 2010), con lo cual se obtuvo los valores de afinidad entre el péptido con una serie de enzimas asociadas a los patógenos de interés y con moléculas presentes en la membrana celular bacteriana.

\section{RESULTADOS}

A partir de la secuencia de aminoácidos que conforman la Cruzioseptina CC-17 obtenida previamente por el Laboratorio de Biología Molecular y Bioquímica de la Universidad Regional Amazónica IKIAM mediante técnicas de clonación molecular y secuenciamiento por espectrometría de masas en tándem se llevó a cabo la parte inicial del estudio computacional del péptido que engloba la predicción de propiedades fisicoquí- 
micas las cuales se presentan en la Tabla 1. Por otra parte, la Tabla 2 presenta la nomenclatura de los distintos aminoácidos que conforman la secuencia del péptido.

Tabla 1. Propiedades fisicoquímicas de la Cruzioseptina CC-17

\begin{tabular}{cc}
\hline Parámetro & Cruzioseptina CC-17 \\
\hline Secuencia de aminoácidos & GFLDVVKGVGKAALGAVTHLINQ-NH 2 \\
Peso molecular (Unidades) & 23 \\
Punto isoeléctrico & 2307,69 \\
Formula & 8,6 \\
Número de átomos & $\mathrm{C}_{105} \mathrm{H}_{175} \mathrm{~N}_{29} \mathrm{O}_{29}$ \\
Aminoácidos de carga negativa & 338 \\
Aminoácidos de carga positiva & 1 \\
Carga & 2 \\
Hidrofobicidad & 3,1 (básica) \\
Momento hidrofóbico & 0,492 \\
& 0,429 \\
Composición de la secuencia en porcentaje & Neutral: $30,43 \%$ \\
& Básica: $13,04 \%$ \\
& Ácida: $4,35 \%$ \\
& Hidrofóbica: $52,17 \%$ \\
\hline
\end{tabular}

Tabla 2. Nomenclatura de aminoácidos que forman parte de la estructura de la Cruzioseptina CC-17

\begin{tabular}{ccc}
\hline Aminoácido & Código de tres letras & Código de una letra \\
\hline Glicina & Gly & $\mathrm{G}$ \\
Fenilalanina & $\mathrm{Phe}$ & $\mathrm{F}$ \\
Leucina & $\mathrm{LeU}$ & $\mathrm{L}$ \\
Ácido aspártico & $\mathrm{Asp}$ & $\mathrm{D}$ \\
Valina & $\mathrm{Val}$ & $\mathrm{V}$ \\
Lisina & $\mathrm{Lys}$ & $\mathrm{K}$ \\
Alanina & $\mathrm{Ala}$ & $\mathrm{A}$ \\
Treonina & $\mathrm{Thr}$ & $\mathrm{T}$ \\
Histidina & $\mathrm{His}$ & $\mathrm{H}$ \\
Isoleucina & $\mathrm{le}$ & $\mathrm{I}$ \\
Asparagina & $\mathrm{Asn}$ & $\mathrm{N}$ \\
Glutamina & $\mathrm{Glu}$ & $\mathrm{Q}$ \\
\hline
\end{tabular}


Se puede notar que el péptido presenta una carga neta de $+3,1$ así como también que en la cadena peptídica se encuentra presente un aminoácido de carga negativa y dos aminoácidos de carga positiva. Adicionalmente, se evidencia que la secuencia correspondiente a la Cruzioseptina CC-17 es en su mayoría hidrofóbica.

En la Figura 1 expuesta a continuación se observa el gráfico correspondiente a la probabilidad de superficie en la cual se aprecia que las ventanas de aminoácidos 1 y 11 son aquellas que tienen la mayor probabilidad de estar en la superficie del péptido, por lo que son las que tienden a interacciones con otras moléculas.

Adicionalmente, al estudiar la flexibilidad del péptido, se observa que esta presenta un valor que oscila entre 0,92 y 1,02 y su punto máximo corresponde a la posición 12 de la ventana de aminoácidos.
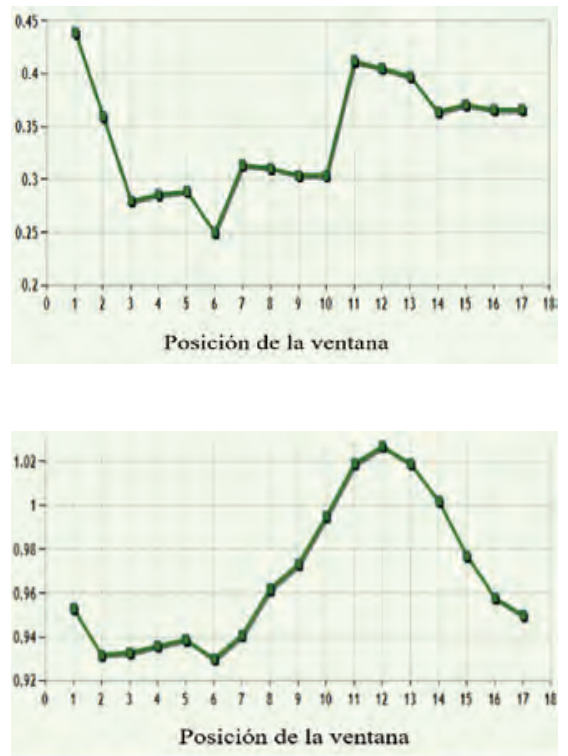

Figura 1. Propiedades fisicoquímicas de la Cruzioseptina CC-17 a. Probabilidad de superficie b. Flexibilidad del péptido en función de la secuencia de aminoácidos

(Bio-Synthesis, 2010)

En la Tabla 3 se muestran los resultados de la predicción de la estructura secundaria del péptido realizada mediante distintas herramientas web, cuyos resultados demuestran que en la Cruzioseptina CC-17 predomina la estructura alfa helicoidal y además se evidencia la presencia de regiones con giros beta tanto al inicio como al final de la cadena de aminoácidos que compone al péptido. 
Tabla 3. Estructura secundaria de la Cruzioseptina CC-17 predicha mediante JPred4 y Predict Protein

\begin{tabular}{|c|c|c|c|c|c|c|c|c|c|c|c|c|c|c|c|c|c|c|c|c|c|c|c|c|c|c|}
\hline Software & & & & Es & ruc & tura & sec & cund & lari & a pr & edi & cha & par & la & Cru & zios & septi & ina & $\mathrm{CC}-$ & 17 & & & & \#аa & $\begin{array}{c}\text { Hélice } \\
\text { alfa } \\
{[\%]}\end{array}$ & $\begin{array}{c}\text { Giros } \\
\text { beta } \\
{[\%]}\end{array}$ \\
\hline \multirow{2}{*}{ JPred4 } & $\mathrm{t}$ & $\mathrm{t}$ & $\mathrm{h}$ & $\mathrm{h}$ & $\mathrm{h}$ & $\mathrm{h}$ & $\mathrm{h}$ & $\mathrm{h}$ & $\mathrm{h}$ & $\mathrm{h}$ & $\mathrm{h}$ & h & $\mathrm{h}$ & $\mathrm{h}$ & $\mathrm{h}$ & $\mathrm{h}$ & $\mathrm{h}$ & $\mathrm{h}$ & $\mathrm{h}$ & $\mathrm{h}$ & $\mathrm{h}$ & $\mathrm{t}$ & $\mathrm{t}$ & 23 & \multirow{2}{*}{82,6} & \multirow[b]{2}{*}{17,4} \\
\hline & G & F & L & $\mathrm{D}$ & $\mathrm{v}$ & $\mathrm{v}$ & $\mathrm{K}$ & G & $\mathrm{v}$ & G & K & A & A & $\mathrm{L}$ & G & A & V & $\mathrm{T}$ & $\mathrm{H}$ & L & I & $\mathrm{N}$ & Q & $-\mathrm{NH}_{2}$ & & \\
\hline Predict & t & t & h & $\mathbf{h}$ & h & h & h & h & h & h & $\mathbf{h}$ & $\mathbf{h}$ & h & $\mathbf{h}$ & $\mathbf{h}$ & $\mathbf{h}$ & $\mathbf{h}$ & h & $t$ & t & $\mathbf{t}$ & $t$ & $t$ & 23 & \multirow[b]{2}{*}{69,6} & \multirow[b]{2}{*}{30,4} \\
\hline Protein & G & $\mathrm{F}$ & L & D & v & $\mathrm{v}$ & $\mathrm{K}$ & G & $\mathrm{V}$ & G & $\mathrm{K}$ & A & A & L & G & A & v & T & $\mathrm{H}$ & $\mathrm{L}$ & I & $\mathrm{N}$ & Q & $-\mathrm{NH}_{2}$ & & \\
\hline
\end{tabular}

Con base en los resultados de la predicción de la estructura secundaria de la Cruzioseptina CC-17, el péptido fue modelado y una vez obtenida la estructura tridimensional se llevó a cabo la optimización geométrica y minimización energética, con lo que se obtuvo la conformación más estable del péptido que se muestra en la Figura 2. En este contexto, se debe resaltar que la estructura optimizada concuerda con las predicciones realizadas previamente, pues se encuentra conformada por una región alfa helicoidal mayoritaria.

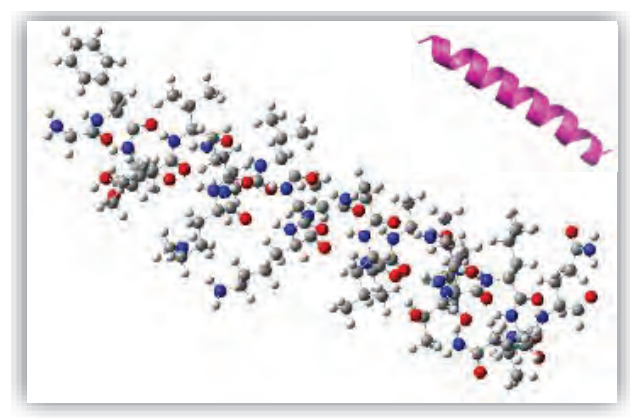

Figura 2. Estructura tridimensional de la Cruzioseptina CC-17 optimizada mediante el método ONIOM HF/3-21G//HF/6-31G

Asimismo, se llevó a cabo el estudio de acoplamiento molecular (Docking), en donde se analizó el valor de afinidad del péptido con distintas enzimas presentes en la membrana celular de los patógenos de interés, los 
cuales fueron comparados con los puntajes de afinidad de los inhibidores conocidos. Se observa que el péptido presenta mayor afinidad con la Proteína de unión de Penicilina Transglicosidada 1b, la cual es una enzima presente en la membrana celular de Escherichia coli y con la Hidrolasa AmiA presente en Staphylococcus aureus (Tabla 4).
Cabe resaltar que en todos los casos la afinidad del inhibidor es mayor que la del péptido, sin embargo, se considera que el puntaje obtenido durante el acoplamiento al hacer referencia al valor predicho de la energía libre de la unión enzima-ligando no permite determinar con certeza el grado de afinidad entre estos dos compuestos, sino que más bien permite clasificar entre ligandos activos e inactivos (Aguayo-Ortiz \& Fernández-de Gortari, 2018).

Tabla 4. Valores de afinidad de la Cruzioseptina CC-17 con distintas enzimas presentes en la membrana celular de Staphylococcus aureus, Escherichia coli y Candida albicans

\begin{tabular}{|c|c|c|c|c|}
\hline \multirow[b]{2}{*}{ Microorganismo } & \multirow[b]{2}{*}{ Enzima } & \multirow{2}{*}{$\begin{array}{l}\text { Inhibidor } \\
\text { conocido }\end{array}$} & \multicolumn{2}{|c|}{$\begin{array}{l}\text { Puntaje de afinidad } \\
\text { (kcal/mol) }\end{array}$} \\
\hline & & & $\begin{array}{l}\text { Inhibidor } \\
\text { conocido }\end{array}$ & $\begin{array}{l}\text { Cruzioseptina } \\
\text { CC-17 }\end{array}$ \\
\hline \multirow[b]{2}{*}{$\begin{array}{l}\text { Staphylococcus } \\
\text { aureus }\end{array}$} & Proteína de unión de Penicilina g-Acil 2A & Ceftobiprol & $-9,5$ & $-5,5$ \\
\hline & Hidrolasa AmiA & $\begin{array}{c}\text { Muramil } \\
\text { tetrapéptido }\end{array}$ & $-7,1$ & $-5,9$ \\
\hline \multirow[b]{2}{*}{ Escherichia coli } & $A D N$ girasa $B$ & ADP & $-10,4$ & $-5,1$ \\
\hline & $\begin{array}{l}\text { Proteína de unión de Penicilina } \\
\text { Transglicosidada lb }\end{array}$ & Moenomicina & $-7,3$ & $-6,3$ \\
\hline \multirow{2}{*}{ Candida albicans } & Exo-B-(1,3)-glucaneasa & Castanospermina & $-7,0$ & $-5,6$ \\
\hline & Proteasa aspártica secretada & A70* & $-7,7$ & $-5,9$ \\
\hline
\end{tabular}

*A70: N-etil-N-[(4-metilpiperazin-1-yl) carbonil]-D-fenilalanil-N-[(1S,2S,4R)-4-(butilcarbamoil)-1-(ciclohexilmetil)-2-hidroxi-5-metilhexil]-L-norleucinamida

Para realizar un estudio más profundo, se realizó el acoplamiento mole- cular entre la Cruzioseptina CC-17 y once moléculas presentes en la mem- 
brana celular de los tres microorganismos estudiados. Los resultados se encuentran detallados en la Tabla 4 en donde se evidencia que los valores de afinidad son variables, pues oscilan entre $-2,0$ y $-3,8 \mathrm{kcal} / \mathrm{mol}$, lo cual se debe en gran medida a la diferencia de tamaño y distribución de cargas en cada una de las moléculas presentes en la membrana bacteriana.

Tabla 5. Valores de afinidad de la Cruzioseptina CC-17 con distintas enzimas presentes en la membrana celular de Staphylococcus aureus, Escherichia coli y Candida albicans

\begin{tabular}{cc}
\hline Moléculas de la membrana celular & $\begin{array}{c}\text { Afinidad (kcal/mol) } \\
\text { Cruzioseptina } \\
\text { CC-17 }\end{array}$ \\
\hline Ácido teicoico & $-2,8$ \\
Beta 1-3 glucano & $-3,2$ \\
Fosfatidiletanolamina & $-2,3$ \\
Glicofosfolípidos & $-3,8$ \\
Fosfomanolípido & $-2,7$ \\
Glicofosfolípido GPLs & $-2,0$ \\
Lisil-fosfatidilglicerol & $-2,8$ \\
Ácido mirístico & $-2,8$ \\
Ácido oleico & $-2,6$ \\
Ácido palmítico & $-2,8$ \\
Ácido palmitoleico & $-2,3$ \\
Fosfatidilglicerol & \\
\hline
\end{tabular}

\section{DISCUSIÓN}

Las Cruzioseptinas caracterizadas a partir de la secreción cutánea de la rana Cruziohyla Calcarifer, son una familia de péptidos muy diversa que se caracterizan por poseer una se- cuencia $\mathrm{N}$-terminal única compartida. En este sentido, las propiedades fisicoquímicas expuestas en la Tabla 1 permiten clasificar a la Cruzioseptina CC-17 como un péptido antimicro- 
biano conformado por 23 aminoácidos y que destaca por ser catiónico y básico. Además, posee un C-terminal amida que le otorga una carga positiva adicional al péptido atribuyéndose así una carga neta de $+3,1$, la cual es fundamental en la selectividad del péptido (Bahar \& Ren, 2013), pues al estar relacionada con el número de grupos ionizables del péptido se constituye como un factor que favorece la interacción electrostática que es la principal fuerza de atracción que motiva el primer contacto entre el péptido y la membrana bacteriana (Jindal et al., 2014).

Al analizar la conformación de la cadena peptídica se evidencia la presencia de lisina e histidina, los cuales conceden el carácter básico al péptido y constituyen el $13,04 \%$ de la secuencia de aminoácidos, asimismo, se observa la presencia de ácido aspártico el cual además de contribuir con una carga negativa constituye el 4,35\% de la secuencia peptídica.

La Tabla 1 también permite evidenciar que un 52,17\% corresponde a aminoácidos hidrofóbicos lo que se justifica debido a la presencia mayo- ritaria de alanina y valina junto con un menor número de residuos de leucina, isoleucina y fenilalanina, los cuales gobiernan la capacidad del péptido para ingresar a la bicapa lipídica de la membrana microbiana. Finalmente, el 30,43\% restante de la secuencia corresponde a aminoácidos neutrales lo cual está determinado por la presencia de glicina, treonina, asparagina y glutamina que son aminoácidos conocidos por aportar grupos funcionales polares que tienden a la formación de puentes de hidrógeno (Garret \& Grishman, 2017; Li, Vorobyov, \& Allen, 2013).

Como parte de la caracterización del péptido se analizó la probabilidad de superficie, en donde se nota que la ventana 1 y 11 son las que presentan la tendencia a estar más expuestas (Bio-Synthesis, 2010). Tanto la ventana 1 como la 11 se encuentran formadas principalmente por aminoácidos hidrofóbicos (alanina, leucina, glicina y valina) los cuales tienden a estabilizar la cadena y por ende no sufren cambios drásticos al momento del plegamiento del péptido y hacen efectiva la inserción en el núcleo hidrofóbico de la membrana celular bacteriana lo que aumenta el desor- 
den de los fosfolípidos y causa una disminución en su función protectora (Cantor et al., 2019).

En cuanto a la flexibilidad del péptido se determinó que la región comprendida por la posición de ventanas 10 y 14 corresponden a la zona más flexible mientras que la posición 6 es la más rígida lo cual se debe a que al estar conformada por la cadena VKGVGK* en donde existe igual número de aminoácidos básicos con carga positiva, neutros e hidrofóbicos se tiene una conformación más estable y por ende con menor tendencia a ser desestabilizada (Rončević et al., 2018).

Con base en los resultados de flexibilidad del péptido, se puede determinar que la zona central de la Cruzioseptina CC-17 es la región más flexible, lo cual es poco común para este tipo de moléculas, en donde generalmente las regiones más flexibles son los extremos de la cadena peptídica, sin embargo, esta característica sugiere la existencia de movimientos rotacionales de las cadenas laterales del péptido al momento de la interacción con proteínas o moléculas de la membrana celular bacteriana, lo que se relaciona con una mejor inserción del péptido en el bolsillo enzimático (Babii et al., 2017).

Al analizar los resultados de las predicciones de la estructura secundaria del péptido presentados en la Tabla 2 , se determinó que este se encuentra formado en su mayoría por una región alfa helicoidal, la cual representa entre el 69,6 y el $82,6 \%$ de la estructura total, mientras que el porcentaje restante corresponde a las zonas extremas, en donde existen residuos que adquieren una conformación correspondiente a giros beta, lo cual se relaciona con la formación de puentes de hidrógeno entre el primer y el cuarto aminoácido de la cadena peptídica (Borah, Deb \& Chakraborty). La predominancia de la estructura alfa helicoidal se debe a la presencia de aminoácidos neutrales e hidrofóbicos, los cuales tienden a la formación de puentes de hidrógeno entre los átomos de oxígeno del grupo carbonilo de un aminoácido y el átomo de hidrógeno del grupo amino de otro aminoácido, obteniendo así una configuración estable (Arakawa \& DeForest, 2017). 
Al contrastar las predicciones realizadas con la estructura optimizada de la Cruzioseptina CC-17 (Figura 2), se evidencia la existencia de una gran similitud, pues la gran mayoría de aminoácidos adquieren la conformación alfa helicoidal, siendo solamente los dos primeros (-GF) ${ }^{*}$ y los dos últimos (-NQ)* residuos de la cadena peptídica, los que sufren una desestabilización y en lugar de adquirir una conformación relacionada con los giros beta se constituyen como colas randómicas que se caracterizan por ser estructuras muy flexibles que facilitarán el ingreso del péptido al bolsillo enzimático.

En cuanto a los mecanismos de acción de los péptidos antimicrobianos, existen una gran variedad de teorías, sin embargo, dentro de estas se pueden distinguir dos grupos que son los mecanismos de modulación inmunológica y aquellos de ataque directo a la membrana celular bacteriana. (Kumar et al., 2018).

En este sentido, se llevó a cabo el estudio de acoplamiento molecular de la Cruzioseptina CC-17 con una serie de enzimas, para conocer si el péptido ejerce un mecanismo de ataque indirecto basado en la inhibición enzimática mientras que el acoplamiento con moléculas presentes en la membrana celular bacteriana se realizó con el fin de estudiar un mecanismo de acción enfocado en el ataque directo a la membrana.

Los resultados mostrados en la Tabla 3 demuestran que la Cruzioseptina CC-17 tiene una mayor afinidad con la Hidrolasa AmiA, la proteína de unión de Penicilina Transglicosidada 1 b y la proteasa aspártica secretada, sin embargo, se evidencia que, en todos los casos, el péptido tiene menos afinidad que los inhibidores.

\footnotetext{
*Véase nomenclatura en Tabla 2.
} 
a)

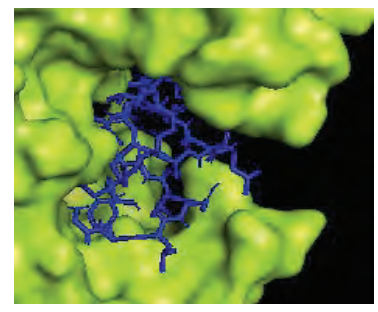

b)

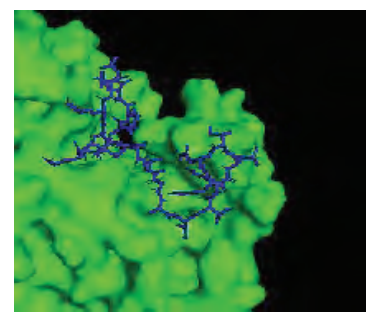

c)

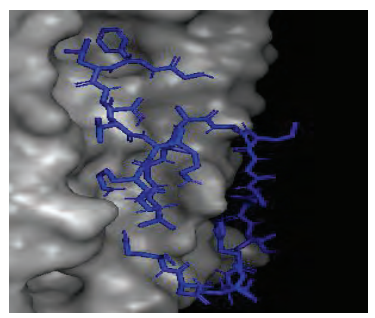

Figura 3. Interacción de la Cruzioseptina CC-17 (azul) con

a). Proteasa aspártica secretada (amarillo)

b). Proteína Transglicosidada 1b (verde) c). Hidrolasa AmiA (gris)

En la Figura 3 inciso a), se observa que la Cruzioseptina CC-17 se acopla a la forma del bolsillo enzimático, lo cual se debe en mayor medida a los cambios rotacionales de las cadenas laterales de la estructura. Además, se evidencia que la parte central es la que logra una mayor interacción con el sitio activo enzimático, sin embargo, el péptido no logra la inhibición dado que la Proteasa Aspártica forma parte de las enzimas hidrolasas cuya función catalítica es la hidrólisis de las cadenas peptídicas (Dunn, 2013). En el inciso b) se evidencia una buena interacción superficial entre el péptido y la enzima debido a la buena exposición del bolsillo enzimático, sin embargo, el péptido no logra cubrir por completo el sitio activo lo cual se justifica dado que la Cruzioseptina CC-17 presenta un tamaño reducido en comparación con el inhibidor conocido (Moenomicina). Por último, en el inciso c) se observa una interacción superficial que está relacionada con la existencia fuerzas electrostáticas entre el péptido y el sitio activo, sin embargo, se considera que el péptido no ingresa al bolsillo enzimático debido a la marcada diferencia entre la longitud de cadena del inhibidor conocido (conformado por 4 aminoácidos) y la de la Cruzioseptina CC-17 (Cuesta et al., 2019). 


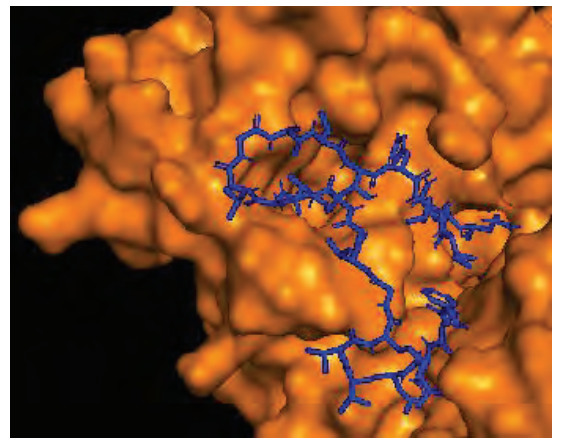

Figura 4. Interacción de la Cruzioseptina CC-17 (azul) con la enzima ADN girasa (naranja)

En el caso del acoplamiento con la ADN Girasa (Figura 4) se nota que la Cruzioseptina CC-17 tiende a interaccionar con el bolsillo enzimático, siendo los residuos de lisina cargados positivamente los que mantienen una interacción marcada en el sitio activo. Cabe aclarar que existe una diferencia muy marcada entre el valor de afinidad del péptido y el ADP, la que se debe en su mayoría a la diferencia de carga entre el inhibidor conocido que presenta carga negativa y el péptido con carga +2 (Cuesta et al., 2019).

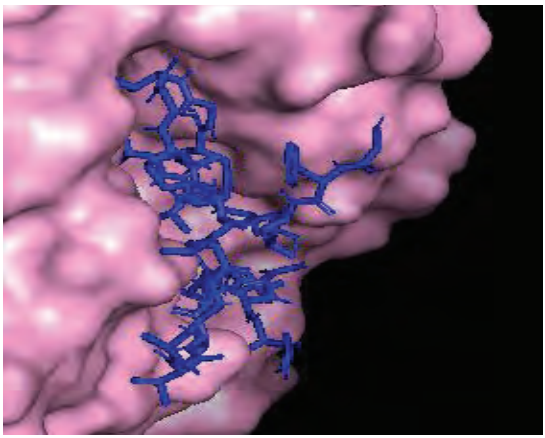

Figura 5. Interacción de la Cruzioseptina CC-17 (azul) con la enzima Exo-B-(1,3)glucanasa (rosa)

En la Figura 5 se observa que en el acoplamiento de la enzima Exo-B$(1,3)$-glucanasa con la Cruzioseptina CC-17, ésta ingresa al sitio activo debido a que el bolsillo enzimático es lo suficientemente amplio y se considera que el mecanismo de inhibición en este caso se logra ya que el péptido recubre el sitio activo y por ende la enzima no es capaz de hidrolizar glucanos, lo que interrumpe la provisión de energía a la célula causando así un desbalance en la misma que al final desencadena en un proceso de lisis celular (Ramos \& Malcata, 2011).

Por otra parte, cabe destacar que en el acoplamiento con la Proteína de 
unión de Penicilina G-acil 2 no existe inhibición debido a que el péptido presenta un mayor número de átomos en comparación con el inhibidor lo que dificulta la entrada de la Cruzioseptina CC-17 en el sitio activo, además existe una diferencia de cargas significativas pues la Cruzioseptina $\mathrm{CC}-17$ a $\mathrm{pH} 7$ presenta una carga de $+1,1$ mientras que la carga del inhibidor presenta un valor de -1 .

Por último, al analizar los resultados obtenidos después del acoplamiento con distintas moléculas presentes en la membrana celular bacteriana, se evidencia que los valores de afinidad son relativamente bajos y oscilan entre -2,0 y -3,8 kcal/mol, lo que denota la existencia de una interacción leve entre ambas moléculas. Hay que considerar que la monocapa lipídica que constituye superficialmente a la membrana celular bacteriana se encuentra formada por compuestos que se caracterizan por poseer lípidos con grupos cargados, entre los que se destacan glicofosfolípidos junto con fosfoaminolípidos (Strahl \& Errington, 2017) y presentan una buena interacción con el péptido debido a que este presenta una carga neta positiva y por ende, son capaces de generar una ruptura de la pared celular, siendo este el mecanismo de acción más viable.

Además, la hidrofobicidad de la cadena peptídica es un factor clave pues esta dictamina hasta qué punto el péptido será soluble en agua y podrán dividirse en la bicapa lipídica de la membrana, es por esto que se considera que la Cruzioseptina CC-17 al poseer una composición mayormente hidrofóbica, tendrá la capacidad de generar una ruptura de la membrana bacteriana externa continuando con un ataque a la membrada interna (Kumar et al., 2018).

\section{CONCLUSIÓN}

Con base en el modelamiento computacional de la Cruzioseptina CC17 extraída a partir del exudado de la rana Cruziohyla calcarifer, se determinó que sus propiedades fisicoquí- micas concuerdan con la de compuestos bioactivos previamente estudiados pues presenta una cadena peptídica conformado por 23 aminoácidos es de carácter básico, pues 
presenta una carga de $+3,1$ así como también se destaca por poseer un punto isoeléctrico de 8,6. Adicionalmente, se estableció que la interacción entre el péptido, las enzimas y las moléculas de la membrana celular bacteriana se encuentra determinada por la presencia de un $52 \%$ de aminoácidos hidrofóbicos junto con la presencia de aminoácidos básicos, lo cual también permite caracterizar a este compuesto bioactivo como un péptido antimicrobiano catiónico. Por otra parte, los estudios de acoplamiento molecular sugieren que un mecanismo de acción relacionado con la inhibición enzimática no es viable, debido a factores relacionados principalmente con el tamaño del péptido y su carga, por esto se considera que un mecanismo de acción aceptable es el centrado en el ataque a la membrana dentro del cual intervienen atracciones electrostáticas que tienen lugar entre las regiones del péptido con carga positiva y los componentes de la membrana que presentan cargas negativas debido a la presencia de grupos fosfatos, lo que sugiere que el péptido podría ser usado potencialmente en combinación con antibióticos para aumentar tanto su efectividad como su selectividad.

\section{AGRADECIMIENTOS}

Este trabajo tuvo financiamiento de la Pontificia Universidad Católica del
Ecuador a través del proyecto QINV0180-IINV529020200.

\section{LISTA DE REFERENCIAS}

Aguayo-Ortiz, R., \& Fernández-de Gortari, E. (2018). Overview of Computer-Aided Drug Design for Epigenetic Targets. Epi-Informatics. En Ranganathan, S.,Nakai, K., Schonbach, C. Encyclopedia of Bioinformatics and Computational Biology (1st ed, 21-52). Oxford: Elsevier.

Arakawa, C. K., \& DeForest, C. A. (2017). Polymer Design and Development. En Vishwakarma, A. \& Karp, J (Ed). Biology and Engineering of Stem Cell Niches (1st ed, 295-314). Massachusetts: Academic Press 
Babii, O., Afonin, S., Schober, T., Komarov, I., \& Ulrich, A. (2017). Flexibility vs rigidity of amphipathic peptide conjugates when interacting with lipid bilayers. Biochimica et Biophysica Acta (BBA) - Biomembranes, 1859(12), 2505-2515.

Bahar, A., \& Ren, D. (2013). Antimicrobial Peptides. Pharmaceuticals, 6(12), 1543-1575.

Berman, H., Battistuz, T., Bhat, T., Bluhm, W., Bourne, P., Burkhardt, K., Feng, Z., Gilliland, G., Iype, L., Jain, S., Fagan, P., Marvin, J., Padilla, D., Ravichandran, V., Schneider, B., Thanki, N., Weissig, H., Westbrook, J., \& Zardecki, C. (2002). The Protein Data Bank. Acta Crystallographica. Section D, Biological Crystallography, 58(Pt 6 No 1), 899-907.

Bio-Synthesis. (2010). Peptide Calculator. https://www.biosyn .com/peptidepropertycalculatorl anding.aspx

Borah, A., Deb, B. \& Chakraborty, S. A Crosstalk on Antimicrobial Peptides. International Journal of Peptide Research and Therapeutics, 27 (2021), 229-244.

Cantor, S., Vargas, L., Rojas A., O., Yarce, C., Salamanca, C., \& Oñate-Garzón, J. (2019). Evaluation of the Antimicrobial Activity of Cationic Peptides Loaded in SurfaceModified Nanoliposomes against Foodborne Bacteria. International Journal of Molecular Sciences, 20(3), 680. doi:10.3390/ijms20030680

CDC. (2020). Antibiotic-Resistant Germs: New Threats. Recuperado 27 de septiembre de 2020 de https://www.cdc. gov/drugresistance/biggest-threats.html

Cuesta, S., Gallegos, F., Arias, J., Pilaquinga, F., Blasco-Zúñiga, A., Proaño-Bolaños, C., Rivera, M., \& Meneses, L. (2019). Modelamiento molecular de la dermaseptina SP2 extraída de Agalychnis spurrelli. Infoanalítica, 7(1), 41-56.

Datta, S., \& Roy, A. (2020). Antimicrobial Peptides as Potential Therapeutic Agents: A Review. International Journal of Peptide Research and Therapeutics, 27(2021), 555577.

De Paula, V. S., \& Valente, A. P. (2018). A Dynamic Overview of Antimicrobial Peptides and Their Complexes. Molecules, 23(8), 1-13. 
Demori, I., Rashed, Z. E., Corradino, V., Catalano, A., Rovegno, L., Queirolo, L., Salvidio, S., Biggi, E., Zanotti-Russo, M., Canesi, L., Catenazzi, A., \& Grasselli, E. (2019). Peptides for Skin Protection and Healing in Amphibians. Molecules, 24(2),1-15.

Drozdetskiy, A., Cole, C., \& Procter, J. (2015). JPred4: A protein secondary structure prediction server. https://www.ncbi.nlm.nih.gov/pmc/articles/PMC4489285/

Dunn, B. M. (2013). Aspartic Proteases. Encyclopedia of Biological Chemistry, 1(1), 123127.

Garret, R., \& Grishman, C. (2017). Biochemistry. Virginia: CENGAGE Learning.

Faivovich, J., Haddad, C., García, P., Frost, D., Campbell, J., \& Wheeler, W. (2005). Sistematic Review of the Frog Family Hylidae, with Special Reference to Hylinae: Phylogenetic Analysis and Taxonomic Revision. New York: American Museum of Natural History.

Frisch, M., Trucks, G., Schlegel, H., Scuseria, G., Robb, M., Cheeseman, J., Scalmani, G., Barone, V., \& Petersson, G. (2016). Gaussian 09, Revision C.01. Gaussian, Inc.

Jindal, M., Le, C., Mohd, M., \& Sekaran, S. (2014). Net Charge, Hydrophobicity and Specific Aminoacids to the Activity of Antimicrobial peptides. Journal Of Health And Translational Medicine, 17(1), 1-7.

Koehbach, J., \& Craik, D. (2019). The Vast Structural Diversity of Antimicrobial Peptides. Trends in Pharmacological Sciences, 40(7), 517-528.

Kumar, P., Kizhakkedathu, J., \& Straus, S. (2018). Antimicrobial Peptides: Diversity, Mechanism of Action and Strategies to Improve the Activity and Biocompatibility In Vivo. Biomolecules, 8(4), 1-24.

Lear, S., \& Cobb, S. (2016). Pep-Calc.Com: A Set of Web Utilities for the Calculation of Peptide and Peptoid Properties and Automatic Mass Spectral Peak Assignment. Journal of Computer-Aided Molecular Design, 30(3), 271-77.

Lee, T., Hall, K., \& Aguilar, M. (2015). Antimicrobial Peptide Structure and Mechanism of Action: A Focus on the Role of Membrane Structure. Current Topics in Medicinal Chemistry, 16(1), 25-39. 
Lei, J., Sun, L., Huang, S., Zhu, C., Li, P., He, J., Mackey, V., Coy, D., \& He, Q. (2019). The antimicrobial peptides and their potential clinical applications. American Journal of Translational Research, 11(7), 3919-3931.

Lewies, A., Du Plessis, L., \& Wentzel, J. (2019). Antimicrobial Peptides: The Achilles' Heel of Antibiotic Resistance?. Probiotics and Antimicrobial Proteins, 11(2), 370381.

Li, L., Vorobyov, I., \& Allen, T. W. (2013). The Different Interactions of Lysine and Arginine Side Chains with Lipid Membranes. The Journal of Physical Chemistry B, 117(40), 11906-11920.

López, J., Zenak, S., De la Torre, J., Guy, O., Garro, A., \& Enriz, R. (2018). Small Cationic Peptides: Influence of Charge on Their Antimicrobial Activity. ACS Omega, 3(5), 5390-5398.

Ramos, O., \& Malcata, F. (2011). Food-Grade Enzymes. Comprehensive Biotechnology, 555-569. doi:10.1016/b978-0-08-088504-9.00213-0

Morris, G., Huey, R., Lindstrom, W., Sanner, M., Belew, R., Goodsell, D., \& Olson, A. (2009). AutoDock4 and AutoDockTools4: Automated Docking with Selective Receptor Flexibility. Journal of Computational Chemistry, 30(16), 2785-2791.

Museo de Zoología PUCE, (2020). Anfibios del Ecuador. Recuperado 15 de Septiembre de 2020 de https://bioweb.bio/faunaweb/amphibiaweb/

Proaño-Bolaños, C., Blasco-Zúñiga, A., Almeida, J., Wang, L., Llumiquinga, M., Rivera, M., Zhou, M., Chen, T., \& Shaw, C. (2019). Unravelling the Skin Secretion Peptides of the Gliding Leaf Frog, Agalychnis Spurrelli (Hylidae). Biomolecules, 9(11), 120.

Proaño-Bolaños, C, Zhou, M., Wang, L., Coloma, L., Chen, T \& Shaw, C. (2016). Peptidomic approach identifies cruzioseptins, a new family of potent antimicrobial peptides in the splendid leaf frog, Cruziohyla calcarifer. Journal of Proteomics, 146(2016), 1-13.

Raheem, N., \& Straus, S. K. (2019). Mechanisms of Action for Antimicrobial Peptides With Antibacterial and Antibiofilm Functions. Frontiers in Microbiology, 10(2866), 1-14. 
Ramos, O., \& Malcata, F. (2011). Food-Grade Enzymes. En Moo, M (Ed). Comprehensive Biotechnology (2nd ed., pp. 555-569). Massachusetts: Academic Press

Rončević, T., Vukičević, D., Ilić, N., Krce, L., Gajski, G., Tonkić, M., Goić-Barišić, I., Zoranić, I., Sonavane, Y., Benincasa, M., Juretić, D., Maravić, A., \& Tossi, A. (2018). Antibacterial Activity Affected by the Conformational Flexibility in Glycine-Lysine Based $\alpha$-Helical Antimicrobial Peptides. Journal of Medicinal Chemistry, 61(7), 2924-2936.

Schrödinger. (2017). The PyMOL Molecular Graphics System. Schrödinger,LLC.

Seyfi, R., Abarghooi, F., Ebrahimi, T., Montazersaheb, S., Eyvazi, S., Babaeipour, V., \& Tarhriz, V. (2020). Antimicrobial Peptides (AMPs): Roles, Functions and Mechanism of Action. International Journal of Peptide Research and Therapeutics, 26(3), 1451 1463.

Strahl, H., \& Errington, J. (2017). Bacterial Membranes: Structure, Domains, and Function. Annual Review of Microbiology, 71(1), 519-538.

Trott, O., \& Olson, A. (2010). AutoDock Vina: Improving the Speed and Accuracy of Docking with a New Scoring Function, Efficient Optimization, and Multithreading. Journal of Computational Chemistry, 31(2), 455-461.

Varga, J. F., Bui-Marinos, M. P., \& Katzenback, B. A. (2019). Frog Skin Innate Immune Defences: Sensing and Surviving Pathogens. Frontiers in Immunology, 9(3128), 1 21.

Wang G. (2020). Bioinformatic Analysis of 1000 Amphibian Antimicrobial Peptides Uncovers Multiple Length-Dependent Correlations for Peptide Design and Prediction. Antibiotics, 9(8), 1-26.

Yachdav, G., \& Rost, B. (2013). PredictProtein-Protein Sequence Analysis, Prediction of Structural and Functional Features. https://predictprotein.org/

Zhang, C., Yang, M., \& Ericsson, A. (2019). Antimicrobial Peptides: Potential Application in Liver Cancer. Frontiers in Microbiology, 1257(10), 1-10. 